\title{
EMIR RODRÍGUEZ MONEGAL O LA CONSTRUCCIÓN DE UN MUNDO (NUEVO) POSIBLE
}

POR

LUZ RODRÍGUEZ-CARRANZA

Universidad Católica de Lovaina

... todavía nos invaden sus montoneras de jugadores de fútbol de críticos cinematográficos de críticos literarios de críticos diacríticos entre argentina y brasil gime uruguay críticamente. (César Fernández Moreno, "Un argentino de vuelta", en $M N 12,14$ )

\section{LA CRITTICA PERIÓDICA}

La emergencia de una literatura, la presencia sostenida de un grupo de obras, consideradas como un conjunto homogéneo, en los discursos jerarquizados de la cultura occidental es una consagración raramente contemporánea a la producción misma. Ésta es una de las razones por las cuales el caso de la "nueva novela" latinoamericana, de su canonización vertiginosa en sólo una década, es un objeto de estudio apasionante para el comparatista. El boom (y no entraré aquí a discutir el término) trajo consigo una multiplicidad complejísima de fenómenos para-literarios; y entre ellos resulta particularmente interesante el estudio de un discurso crítico de riqueza excepcional en su variedad, en su abundancia y en sus contradicciones, que se perfila en los años 60/70 simultáneamente a la publicación de las obras, provocándolas, estimulándolas y, a veces, precediéndolas. Este trabajo crítico se inició en América Latina, pero la movilidad de los autores dentro del continente, debida en su gran mayoría al exilio, se prolongó en esos años hacia España, Europa y los Estados Unidos, difundiendo sus modelos literarios con celeridad y eficacia.

La afirmación de la existencia de esta actividad puede parecer extraña cuando ya es un lugar común lamentarse por la insuficiencia de la crítica literaria en nuestros países. El carácter mismo de la emergencia y la necesidad de afirmación gradual de su objeto, la literatura latinoamericana, impidieron su homogeneización y autoconciencia. Desperdigada en numerosos países y manifestaciones, aislada y conflictuada política y económicamente; templada en reiteradas crisis de capilla, debatiéndose en la superación de maniqueísmos, 
ejercida frecuentemente por los autores mismos, la crítica vive vigorosamente en las revistas literarias. Y si la cantidad es impresionante, no lo es menos la abundancia de informaciones "en vivo" que nos brindan. Como lo señalan Lambert (1980) y Swiggers (1982), el historiador debe estudiar el circuito literario (producción, distribución, recepción, traducción) para definir la literariedad de los textos según un sistema de normas y de valores en evolución; y en el caso que nos ocupa,

el análisis métodico de las revistas [...] ofrece una fuente excepcional de informaciones primordiales sobre la producción y la vida literarias, tanto del lado autor-editor como del lado del público (Vlasselaers, 1982).

Ahora bien, ¿por dónde empezar?'1 Hemos partido de una hipótesis: en todo discurso social (Angenot, 1984), incluso en ese mare magnum de discursos que es el de las revistas latinoamericanas, hay modelos predominantes que han logrado imponer sus sistemas de valores a los demás, que los han exportado y "vendido" con más eficacia que otros. Éstos son, precisamente, los más coherentes y fáciles de detectar: tienen un programa claro que se destaca nítidamente frente a los partidismos e incongruencias de las periferias. La crítica uruguaya se perfila así como uno de los hilos más fuertes y determinantes en la segunda mitad del siglo, y en ella, desde luego, Marcha es un mojón insoslayable. Puede decirse que sus redactores principales marcaron los rumbos de, por lo menos, dos de las líneas críticas más netas y definidas del continente; y en el caso particular de Emir Rodríguez Monegal, la construcción de un Mundo Nuevo cuyo discurso cobró fuerza y autoridad hasta constituir a fines de los años sesenta uno de los parámetros hegemónicos del modelo triunfante. Mentor indiscutido de unos; blanco obsesional de las diatribas, ataques y calumnias de los otros: nadie fue indiferente a su trabajo.

El estudio de una figura aislada, sin embargo, no puede ser sino parcial ya que sus manifestaciones son entrelazamientos de relaciones que las integran en las diferentes prácticas discursivas de su época. Éste es el caso, particularmente, si nos dedicamos al análisis de la primera etapa en la producción crítica de Rodríguez Monegal como redactor y director de Marcha desde 1943 hasta 1960. En este período no pueden estudiarse sus posiciones individualmente, sino en contrapunto con otras y, particularmente, con las de Ángel Rama (aunque la confrontación, tal comola vislumbro ahora, podría parecerse mucho al desenlace de "Los teólogos", de Borges.) $)^{2}$ También exige un estudio plurívoco, a partir de

\footnotetext{
${ }^{1}$ Este plural "hemos" se refiere a un proyecto de conjunto de investigacion en curso en la Universidad de Lovaina, el cual se han efectuado y se efectúan actualmente diversos estudios sobre revistas latinoamericanas contemporáneas.

${ }^{2}$ Rodríguez Monegal lo utiliza como ejemplo en su artículo sobre Darío y Rodo, "La utopía modernista", en Revista Iberoamericana 112-113(julio-diciembre 1980) 427-442: "ambos" -Darío y Rodó:
} 
julio 1968 y de su nombramiento en Yale, suinserción en lacrítica latinoamericana en los Estados Unidos, junto a Alfredo Roggiano, la Revista Iberoamericana y el Instituto Internacional. Allí encontró posiciones y aspiraciones que coincidieron con las suyas, y su actividad se multiplicó increiblemente hasta su último viaje al Uruguay y su muerte el 14 de noviembre de 1985.

Entre esos dos periodos se encuentra la época de la revista Mundo Nuevo, que es completamente diferente. Él fue el dueño absoluto de su revista: él escogió sus colaboradores, seleccionó sus entrevistas y sus materiales; su función fue la del narrador omnisciente de "un" mundo (entre muchos mundos posibles) que fue su entera creación, y que se rigió según sus propias leyes: resulta absolutamente legítimo, pues, considerarle eje y parámetro de toda lectura de su propio territorio. Me centraré aquí en esta segunda etapa porque es la única que puede estudiarse como un todo independiente, aunque, desde luego, otras perspectivas de lecturas deberán completar la mía para describir las otras voces y las relaciones entre ellas que dinamizan la revista. ${ }^{3}$

\section{MUNDO NUEVO}

La revista, mensual, fue fundada en julio de 1966 en Paris. La impresión que causan sus veinticinco primeros números es la de una conciencia clarísima del proyecto emprendido y de las maneras de realizarlo, sumadas a una eficacia y a una coherencia totales en su ejecución. Rodríguez Monegal ha decidido crear "una literatura" en el sentido en que emplea esta expresión Octavio Paz:

la crítica es lo que constituye eso que llamamos una literatura y no es tanto la suma de las obras como el sistema de sus relaciones: un campo de afinidades y oposiciones $(M N 21,57)$.

... eran hombres cultos y vivieron en las capitales más internacionales de la América Latina de su tiempo; ambos fueron (brevemente) amigos. Pero sus visiones eran, aparentemente, tan opuestas que habitualmente se ha usado una imagen para negar, y hasta destruir, la otra [...] En el cuento de Borges "Los téblogos" dos personajes llegan a la presencia de Dios, y descubren que para la mirada divina son uno y el mismo ser. La Cosmópolis de Darfo y la Isla de Ariel de Rodó habrán parecido a sus autores, asi como a muchos de sus contemporáneos, opuestas e irreconciliables Utopías. Pero a mbas estaban formuladas en el mismo código literario, ambas reflejaban la misma écriture y la misma manera de pensar.

Cambiando "las circunstancias, la hora y uno o dos nombres propios", como concluye Borges en "Emma Zunz", este texto podría utilizarse como epigrafe de un estudio comparativo de la obra de ambos críticos uruguayos.

${ }^{3}$ Ann Opsomer está realizando actualmente el análisis de Mundo Nuevo, incluyendo su "segunda parte"; su estudio, además se relaciona con otras investigaciones de Lovaina aún inéditas sobre las publicaciones del Consejo por la Libertad de la Cultura y del I.L.A.R.I., como el análisis de Cuadernos (1951-1965), efectuado por Kristine Vanneste y Annick Grimon y la tesis doctoral en curso de Kristine Vanden Berghe sobre Cadernos Brasileiros. La confrontación con la tesis doctoral de Nadia Lie, sobre Casa de las Américas, es también necesaria. 
Se trata de crear un espacio intelectual: un contexto, cuyas exigencias se describen con precisión en la primera editorial de Mundo Nuevo. Deberá ser:

a la vez internacional y actual; deberá establecer un diálogo que sobrepase las conocidas limitaciones de nacionalismos, partidos políticos (nacionales o internacionales), capillas más o menos literarias y artísticas.

Esta caja de resonancia permitirá:

recoger en una publicación periódica, verdaderamente internacional, lo más creador que entrega América Latina al mundo para lograr una cultura sin fronteras, libre de dogmas y fanáticas servidumbres $(M N 1,4)$.

La línea de trabajo fue, pues, la construcción de una literatura latinoamericana y cosmopolita, que estableciera una especie de Internacional de la cultura sin dejarse regir ni influenciar por ningún otro criterio que el de su director:

Mundo Nuevo establecerá sus propias reglas de juego, basadas en el respeto por la opinión ajena y la fundamentación razonada de la propia; en la investigación concreta y con datos fehacientes de la realidad latinoamericana, tema aún inédito; en la adhesión apasionada a todo lo que es realmente creador en América Latina.

Tomando esta presentación como punto de partida, veamos los postulados que propone: qué referentes tienen, para Rodríguez Monegal, los términos "internacional", "latinoamericano", "actual", "creador" y "libre de dogmas"; y cuál es la metodología que le permitirá seguir las reglas de "respeto", "rigor" y "apasionamiento" que considera fundamentales. Efectuaré simultáneamente para ello una lectura de las propias opiniones del crítico y un análisis de la revista y de sus materiales.

\section{LAS OPINIONES DE RODRIGUEZ MONEGAL}

\section{A) UNA LITERATURA "LATINOAMERICANA" E "INTERNACIONAL"}

El impacto de la novela latinoamericana en los años sesenta suscitó en el extranjero una imagen unívoca de nuestra producción cultural, y esta simplificación provocó la reacción indignada, no sólo de los nacionalistas autóctonos, sino también de los indigenistas europeos cuya especialización los convertia en defensores de "la diferencia", del color local y del regionalismo: no es lo mismo un gaucho, desde luego, que un maya. Sin embargo, aquellos intelectuales latinoamericanos que habían viajado mucho $\longrightarrow$ que vivían en el exilio- abogaron por la superación de los ghettos y por la intensificación del mestizaje: "el maya" y "el gaucho" no existen en tanto categorías abstractas: se trata de seres humanos complejos, que viven en el siglo XX, como Borges o como 
cualquier europeo. Carlos Fuentes, por ejemplo, alma tutelar de Mundo Nuevo, es presentado como un intelectual que no sólo viajó por Europa, sino también por los Estados Unidos y la Unión Soviética, adquiriendo así la distancia necesaria para ver el conjunto de América Latina sin chauvinismos. Rodríguez Monegal considera que su amplitud de visión le permitió percibir nuestra literatura como la vieron los lectores, editores y críticos extranjeros:

sin parcelarla en pequeños cotos paraguayos, mexicanos, uruguayos y chilenos, sino [...] como un todo orgánico lleno de correspondencias internas y externas $(M N 1,21)$.

También Octavio Paz expresa la misma convicción:

no hay una literatura argentina, chilena o mexicana, sino la literatura de una sola lengua. [...] La América Latina, aunque subdesarrollada, es parte integral de Occidente $(M N$ 3, 73).

Los nacionalismos son duramente fustigados por Rodríguez Monegal. Así, censura a sus colegas de la revista Ercilla, de Chile, con la cual habitualmente las relaciones son inmejorables $(M N 11,88)$. Estos redactores, conjuntamente con los del diario El Siglo, llamaron a críticos y escritores a debatir el problema de la actual novela chilena. El director de Mundo Nuevo, respondiendo al debate, aclara que "es difícil establecer cálculos sobre bases nacionalistas" y propone una visión continental. Su crítica se vuelve irónica y mordaz cuando comenta una reunión similar realizada en Argentina a instancias del diario $E l$ Mundo sobre el tema "realismoy vanguardismo", donde se atacó a la vanguardia del Instituto Di Tella, favorita del apoyo oficial ( $M N$ 6): "la rancia enemistad de pronto se convertiría en fraternal abrazo sobre el terreno, algo inesperado, del nacionalismo", cuya mejor expresión, el peronismo, resulta paradójicamente aceptable para sus adversarios tradicionales ya que "la izquierda abandona su internacionalismo" como afirmó Roberto Cossa. La sorna alcanza incluso a Fernández Moreno, presente en la reunión, autor de un libro poético titulado Argentino hasta la muerte. Ser colaborador fiel de Mundo Nuevo no garantiza la impunidad, e incluso Severo Sarduy, el más actual y vanguardista, quien recibe habitualmente todo el apoyo del director en sus opiniones, le irrita cuando se obstina en hablar de una "búsqueda de la cubanidad" $(M N 2,18)$.

Un grave peligro es la interpretación literal del cosmopolitismo, error frecuente cuando se habla de Dario ( $M N 7)$. La crítica al propio país es una prueba de amor, porque es una autocrítica, y nadie se traiciona a sí mismo reconociendo sus propios defectos. Siniavski y Daniel ( $M N 1$ ), Arthur Miller ( $M N$ 4), Orfila Reynal ( $M N 3,82-83)$ fueron perseguidos por haber atentado contra la "imagen" de los países en los que vivian o trabajaban; Mundo Nuevo busca a un norteamericano, Nisbet, para hablar del plan Camelot ( $M N$ 9, 78-94) porque "el valor autocrítico de un trabajo como éste no necesita ser encarecido" (79). Si se 
critica a la patria es porque nos hace daño, y es sobre esta base que se reivindica la virulencia de Martínez Estrada, precisamente en artículos de César Fernández Moreno, refrendados aquí por la bendición de la revista.

Lo que provocó la irrupción de la literatura latinoamericana en el escenario internacional no fue su temática ni su color local, sino una manera de crear que universalizó lo propio, que permitió trascender el regionalismo incorporando todo lo que de fértil pudiera tener lo extranjero, lo ajeno, lo diferente. La apertura es el signo de los intereses de Mundo Nuevo en el continente y fuera de él. Todos los grandes escritores, y particularmente los de lengua española, han sido criticados por "extranjerizantes" (MN 7, 39): desde Garcilaso, por “italianizante", Góngora, por "latinizante”, Dario, por "afrancesado", Borges por "anglófilo": y han sido precisamente ellos los que han renovado la lengua literaria de su tiempo. El exilio, voluntario o forzoso, resulta casi inevitable para romper el aislamiento en el que vivimos y, como dice Fuentes:

encontrar toda una serie de correspondencias y de afirmaciones en las relaciones abiertas de la cultura $(M N$ 1, 9). Los grandes nombres de la literatura latinoamericana son casi sin excepción gentes que han vivido fuera de su patria una época de su vida,

acota Rodríguez Monegal, porque "cada día se reduce más el espacio para las culturas de provincia". Se puede echar raíces a distancia sobre la propia tierra, aunque también sea posible, como en el caso de Rulfo (la excepción que confirma la regla) encontrar lo universal en un pedacito de tierra.

El cosmopolitismo debe comenzar entre nosotros mismos, enriqueciéndonos con las culturas de los distintos países de América Latina: y para ello hay que intensificar las posibilidades de comunicación. Si bien Mundo Nuevo se interesa por "una visión crítica de lo más nuevo y renovado de la cultura actual" ("Presentación", MN1)incorporando aquellos textos que puedan abrir horizontes, es una revista esencialmente latinoamericana en su orientación y materiales: más de un setenta por ciento de los textos o metatextos que incluye lo son, en sus autores o en su temática, $y$, por sobre todo, como lo veremos en el apartado "Metodología", el nervio de la revista es la vida cultural del continente, cumpliendo así con su propósito de creación de un contexto y de un diálogo.

\section{B) UNA LITERATURA “ACTUAL" Y "CREADORA"}

Diversos géneros son incorporados a la revista, pero su presentación no es la misma. Hay, por ejemplo, una voluntad muy clara de dar a conocer la poesía del continente, y en cada número la producción individual es abundante (con cierta preferencia por los colaboradores habituales, como Fernández Moreno, o por los nuevos amigos, como Sucre, después del Congreso de Caracas). Se percibe un programa bien delineado de presentaciones globales por país: nueva poesía argentina, uruguaya, peruana, etc: no se exige, aparentemente, el 
criterio de internacionalidad que se reclama para la novela. El teatro, el cine, la escultura, la pintura y la arquitectura tienen sus rúbricas, que alternan de número en número a cargo de colaboradores permanentes, mientras que para la política se busca en cada ocasión el redactor más informado. La narrativa, por su parte, es el coto personal del director, quien no vacila, sin embargo, en publicar estudios polémicos ajenos, cuando los considera interesantes como contrapunto a sus propias opiniones o a las de los críticos especializados. ${ }^{4}$

Ha sido muy difundida la división en cuatro promociones de escritores que realizó Rodríguez Monegal en la ponencia del Congreso de Caracas, en julio de 1967: la primera, la de los renovadores, reúne a Borges, Asturias, Carpentier, Yáñez y Marechal, quienes cambiaron poco la factura exterior de la novela, pero efectuaron la liquidación del naturalismo y la proclamación de la obra literaria como obra de ficción. Una vez esta conquista asegurada, la segunda promoción, la de Guimarães Rosa, Otero Silva, Onetti, Sábato, Lezama Lima, Cortázar y Rulfo; la tercera, que incluye a Martínez Moreno, Lispector, Donoso, Fuentes, García Márquez, Cabrera Infante y Vargas Llosa y, finalmente, la cuarta, la de los novísimos, Puig, Sánchez y Sarduy, tienen como preocupación común la estructura de la novela y la transformación del lenguaje.

Entre los cuatro grupos, el más presente en Mundo Nuevo es el tercero, y el cuarto hace su aparición: podemos considerar que el criterio es el de la actualidad, aunque no faltan los "fundadores" favoritos de Rodríguez Monegal, como Guimarães Rosa y Lezama Lima, prácticamente desconocidos fuera de Brasil y de Cuba respectivamente en esos años; Juan Goytisolo y Max Aub son entrevistados para confirmar la universalidad de la nueva literatura "de una misma lengua"; David Viñas, que no es santo de su devoción, está allí para probar la apertura de la revista a las corrientes críticas que no coinciden con ella. Y el criterio fundador de toda referencia a la novedad o calidad de un texto es, sin discusiones, Borges.

Como para muchos otros postulados críticos de Mundo Nuevo, la entrevista bautismal con Carlos Fuentes es clave también para interpretar la concepción de la literariedad que domina la revista: la ficcionalización radical, la evolución

\footnotetext{
${ }^{4}$ Bajo el título de "Perú, ¿un país adolescente?" en $M N$ 4, 91-92, Rodríguez Monegal resume "un interesante debate literario". El crítico y traductor alemán Wolfgang A. Luchting publicó en la revista Oigo un artículo titulado "Retratos de un país adolescente: ¿Por qué?", en el que afirmó que no sólo los personajes, sino los autores mismos del Perú tienen una mentalidad adolescente, causando las reacciones de José Miguel Oviedo y de Carlos Zavaleta. Rodriguez Monegal matiza la interpretación del texto de Luchting, y posteriormente refrenda la competencia del crítico alemán, publicando un estudio suyo, "Crítica paralela: Vargas Llosa y Ribeyro", en $M N$ 8. Otro procedimiento es el que podríamos denominar "la payada": en $M N$ 8, por ejemplo, se publica un artículo de $\mathrm{A}$. Boule-Christauflour sobre Quiroga, llamado "Una historia de locos", que le sirve a Rodriguez Monegal como punto de partida para una reflexión personal, bajo el título de "Una historia perversa".
} 
de la utopía a la epopeya y de ésta al mito como creación total del lenguaje. La literatura no es una transposición de la realidad: es una creación total y gratuita, es ficción, y esta piedra angular borgiana permite superar los dualismos maniqueos del hebraísmo, de los Testamentos y del marxismo, para entrar en el juego consciente de la palabra y de sus poderes $(M N 1,17)$. Si el lenguaje establecido es el instrumento del estatismo y de la injusticia; si es la validación de un sistema caduco, puede cambiar los referentes del mundo destruyéndose y recreándose a sí mismo. Así el blanco más delicioso para los críticos de Mundo Nuevo es el castellano de la Real Academia: los catalanes, como Goytisolo, y los latinoamericanos lo violan y corrompen alegremente, cambiándole no sólo el léxico sino, de ser posible, la sintaxis y los espectros semánticos.

Las técnicas para construir los mundos ficcionales no pueden ser gratuitas ni estáticas. A pesar de estar editada en París, Mundo Nuevo no pierde ocasión de distanciarse del nouveau roman, optando decididamente por una anglofilia crítica y novelesca. El pop, el camp, la parodia, legitimizan la utilización de imágenes culturales provenientes de los comics y de la publicidad, del cine y de los objetos vulgares o cotidianos, en la creación de inmensos puzzles narrativos. "Somos contemporáneos de todos los hombres en las mercancias y las modas [...] participamos apócrifamente de la modernidad," explica Fuentes $(M N 1,14)$. Rodríguez Monegal y Goytisolo distinguen dos modelos tipológicos en la nueva novela: los que llevan a la perfección un determinado procedimiento novelesco, como es el caso de Vargas Llosa, y "los que sugieren una serie de lenguajes sin llevarlos jamás a sus últimas consecuencias", vale decir, el modelo Rayuela (MN 12, 53). En la entrevista con Sábato ( $M N 3$ ) se retoma la distinción de los dos modelos, denominándolos "novela novelesca" y "novela crítica de la novela"; Rodríguez Monegal sostiene que estos modelos han existido siempre (Tom Jones y Tristram Shandy) pero que en la nueva novela se desarrollan utilizando una serie de técnicas que vienen de la novela experimental de los años 20 y 30 , de Joyce, Woolf, Proust, Mann y Faulkner.

Sus preferencias por la literatura anglosajona, y sobre todo, por James, han familiarizado a Rodríguez Monegal con el estudio de las técnicas narrativas. Si bien considera necesario el análisis del "contorno", el director considera -a diferencia de los críticos de la generación de los "parricidas", a quienes "les importa más la realidad de la que parte la obra literaria que la realidad que ésta misma crea" - que no puede dejarse de lado el estudio central de la obra en aquello que tiene de específicamente literario. Y para ello, hay que conocer:

la obra precursora de los formalistas rusos, la labor verdaderamente revolucionaria de la escuela de Cambridge o del New Criticism norteamericano, la obra [...] de los estructuralistas franceses $(M N 18,77)$.

Así, en 1966 y 1967, vale decir, seis años antes de la publicación de Figures III de Genette en Francia, Mundo Nuevo discutía con soltura problemas narratológicos, y los propagandizaba en América Latina. Las discusiones con 
Sábato y con Goytisolo analizan minuciosamente la construcción de sus novelas, como lo hace también el artículo sobre Vargas Llosa ( $M N$ 3). Pero esto, si bien manifiesta la actualidad de la revista en los años del apogeo del estructuralismo, no resulta tan sorprendente como su afirmación reiterada de la historicidad del hecho literario y su insistencia en la contextualización de los análisis, que adelantan tendencias de la crítica de los años ochenta. En 1968, su artículo sobre Lezama Lima, "Paradiso en su contexto" ( $M N$ 24), es totalmente insólito. En unjuego de auto-ironíacrítica, se desarrollan sucesivas lecturas "superficiales" de la obra, desde diferentes perspectivas metodológicas que se organizan comparándose al esquema de cuatro lecturas del Convivio: literal, moral, alegórica y anagógica. Cada uno de los análisis es parcial: pero el conjunto permite una visión compleja del texto. Afirmar el carácter relativo e hipotético de la interpretación en un medio en el que la caza a las isotopías era el deporte favorito y en el cual la existencia de una estructura profunda y única de significado reflejada o representada en las estructuras de superficie era un axioma sagrado, representa un acto pionero de coraje intelectual. Ver en este artículo una semilla deconstruccionista es ir demasiado lejos, ya que Rodríguez Monegal quiere, por sobre todas las cosas, interpretar a un autor: pero se perciben en él, indiscutiblemente, los signos de la posmodernidad.

\section{C) UNA LITERATURA “LIBRE DE DOGMAS"}

Mundo Nuevo afirma en su editorial del número 11: "es una revista que se edita bajo la orientación exclusiva de su director, único responsable de la selección de todo material que publica ${ }^{n}$. El criterio del director es decididamente independiente, y se expresa sin ambages, tanto en lo que hace a los acontecimientos políticos de su época como en lo que se refiere al papel del escritor y de la literatura en ese mundo que le toca vivir.

Desde el punto de vista político e ideológico, Emir Rodríguez Monegal considera la guerra fría como un duelo anacrónico, "de otra era geológica" ( $M N$ 4, 50). En la entrevista "con" Max Aub en $M N 15$ (en la cual el verdadero entrevistado es el entrevistador), define su posición como sigue:

Yo creo ser más auténticamente dialéctico que muchos que se proclaman marxistas, y como soy dialéctico pienso que precisamente si algo puede enseñarnos Hegel es que después que se ha conseguido una síntesis no se ha llegado al punto final sino que se está al comienzo de una nueva serie. La síntesis se convierte en tesis, la que a su vez genera una antítesis y una nueva síntesis, y así sucesivamente. Precisamente, de aquí arranca el error de quienes piensan que un día de octubre de 1917 en la Unión Soviética, o de octubre de 1949 en China, bastan para dividir para siempre el mundo entre los que están a la izquierda y los que están a la derecha. Los que se pasan la vida haciendo el recuento de cómo fulano, que en 1936 estaba $35^{\circ}$ a la izquierda ahora está sólo $34^{\circ}$, o tal vez $28^{\circ}$ a la derecha, ésos cometen el error de creer que el mundo está fijo y no ha cambiado un ápice a partir de una fecha que ellos eligen para siempre. Yo no 
creo que haya nada fijo en este mundo, y tal vez ni siquiera en el otro, si existe (50).

Nada le irrita más que las definiciones y las acusaciones simplistas: los Estados Unidos no son sólo McCarthy, la Unión Soviética no es sólo Stalin, y en todas partes se cometen injusticias y crímenes contra la humanidad. Dicho con palabras de Sábato $(M N 5,21)$ :

Los rusos cometieron tremendos crímenes bajo la tenebrosa tiranía de Stalin, pero, ¿quiénes son para juzgarlos los torturadores de Argelia, los criminales del Congo, los asesinos de Hiroshima, los marines de Santo Domingo, los que arrojan bombas de Napalm en el Vietnam?

La denuncia sistemática se impone en todas partes: pero el apoyo y la simpatía del intelectual deben ir a todos los intentos progresistas y revolucionarios. La importancia de la Revolución Cubana es indiscutible para Mundo Nuevo, a pesar de los anatemas que contra su director pronunciaron Fernández Retamar y Angel Rama, ${ }^{5}$ y cada vez que se trata de afirmar que un escritor cumple con su responsabilidad se citan sus declaraciones a favor de Cuba. Vargas Llosa, por ejemplo, al recibir el premio Rómulo Gallegos hizo un discurso en ese sentido, sin que nadie en la revista hiciera ninguna alusión al hecho de que hubiera recibido ocho mil dólares de una casa norteamericana como anticipo por los derechos de La ciudad y los perros y por la opción a cinco obras más. ${ }^{6}$ Los Estados Unidos no son sólo la C.I.A., sino también intelectuales progresistas de los cuales Arthur Miller representa la quintaesencia:

Miller representa el mejor tipo del escritor norteamericano. Es un hombre que conoce la lucha, que fue perseguido por el maccarthismo en la época en que era simpatizante comunista, que fue perseguido por los comunistas cuando denunció

\footnotetext{
"Ver el intercambio de cartas entre Casa de las Americas y Mundo Nuevo, publicado en la rúbrica "Los dichos y los hechos" de Marcha 1295 del 11 de marzo de 1966 y del 18 de marzo del mismo año, y los artículos de Angel Rama en la misma revista: "El mecenazgo de la C.I.A"., del 6 de marzo de 1966, "Las fachadas culturales”, del 3 de junio de 1966 y "El tigre en el flotante camalote", del 17 de marzo de 1967. Una síntesis de la opinión de Marcha se encuentra en el número 1355 del 3 de junio de 1967: "Historia de una "calumnia". Ver también, de Ambrosio Fornet, "New World in Español", en Casa de las Américas 40, enero-febrero 1967: "Epitafio para un imperio cultural" de Mario Vargas Llosa, en Marcha 1354, del 27 de mayo de 1967 (el mismo artículo fue publicado también en Primera Plana el 30 de mayo del mismo año). La respuesta de Mundo Nuevo se encuentra en "Al lector" en $M N, 11$ de mayo de 1967, "En la C.I.A. y los intelectuales". Editorial de $M N 13$ de julio de 1967 y en "La C.I.A. y los intelectuales", en $M N$ 14, agosto de 1967.

${ }^{6} \mathrm{La}$ información sobre estos derechos de autor no proviene de la crónica del Congreso de Caracas, que se encuentra en $M N$ 17, sino en el № 3, en la presentación del escritor que hace Rodríguez Monegal para su artículo "Madurez de Vargas Llosa": pero alli, precisamente, se la yuxtapone al comentario de su simpatía por la Revolución Cubana.
} 
al aplastamiento de Hungría, y que ahora está en la mejor posición para predicar el acercamiento, la concordia, el diálogo $(M N 4,50)$.

Los buenos y los malos son cosa de cuentos de hadas: y es verdaderamente infantil la imagen que da Mundo Nuevo de los intelectuales cubanos, de sus excomuniones y sus abstenciones. La carta a Pablo Neruda, por ejemplo, regañándolo por haber participado en la reunión del PEN Club en Nueva York en 1966, que fue rechazada con indignación por el poeta chileno. ${ }^{7}$ Fernández Retamar, Director de la revista Casa de las Américas fundó entusiasta, junto con Asturias y con Orfila Reynal, la Comunidad Latinoamericana de Escritores en Génova, en el Congreso del Columbianum de 1965. Sin embargo, en el Congreso de esta flamante Comunidad en México, en 1967, "el cuento de miedo estuvo a cargo de Emmanuel Carballo, que veía la mano de la C.I.A. detrás del asunto y una tremebunda conspiración de la derecha" $(M N 13,76-77$, citando a Benito Milla). Carballo, "había regresado de Cuba poco antes" y tuvo eco inmediato: una declaración de Benedetti, en nombre de veinte escritores entre los que figuraba la delegación cubana en pleno, el chileno Manuel Rojas y el uruguayo Martínez Moreno en la que se retiran del Congreso, porque "hoy en día no se puede pretender que un escritor de izquierda integre la misma Comunidad que otro, de militancia pro imperialista". La reacción de Asturias fue enérgica, recordando que la Comunidad se había creado siguiendo el ejemplo de la europea, en la cual participaban los escritores del este y los países capitalistas. Y agrega la reseña de Milla citada por Mundo Nuevo:

En su desarrollo posterior el Congreso iba a demostrarle al grupo cubano y a sus amigos que no necesitaba de su estrategia compulsiva para hacer frente con dignidad a los problemas políticos reales que vive América Latina.

La antinomia sartreana "no hay lugar para la literatura en un mundo de hambre, de Vietnam y de Santo Domingo", es demasiado fácil. La tarea del escritor es formularla a la inversa: sí, debe haber lugar para Vietnam y Santo Domingo en la literatura. Hay que hablar de ello, mal que les pese a los maccarthistas de derecha o a los comisarios culturales de izquierda. Y, si somos partidarios del socialismo, dice Vargas Llosa:

nosotros queremos, como escritores, que el socialismo acepte la literatura. Ella será siempre, no puede ser de otra manera, de oposición ( $M N 1$ 1, 95, reproduciendo un texto de Marcha del 3-4-66).

7 Rodríguez Monegal no se pronuncia en este caso, y prefiere citar un texto irónico de Benito Milla, cuya censura de Benedetti resulta más "legítima" por tratarse de un uruguayo en Uruguay. 
La literatura se rebelará con sus propias armas, que no son las del panfleto. El realismo socialista es blanco de todos los anatemas de Rodríguez Monegal, porque la literatura no es la reproducción de la realidad según los códigos a los que estamos más acostumbrados, que nos parecen, por habituales, los más "verdaderos". Ese es el lenguaje esclerosado que eterniza una imagen estática del mundo tal como está organizado por los que mandan. Pero las relaciones entre las figuras, los modelos, pueden romperse: y la tarea del escritor es percibir las fisuras y acentuarlas en el texto, mostrando la vida en su dinamismo y en su cambio incesante.

\section{METODOLOGIA}

En su estudio sobre Octavio Paz ( $M N$ 21) Rodríguez Monegal distingue dos concepciones diferentes de la crítica, que se complementan. Por un lado, la creación de un "doble" de la obra misma, su apertura a la infinita lectura, a las múltiples interpretaciones, que como se ha visto ya, es ejercida, preferentemente sobre la narrativa, por el director de Mundo Nuevo, y por otra parte, la creación de un ámbito intelectual, estableciendo relaciones entre los textos. "No es casual" -declara Rodríguez Monegal:

que algunos de los más importantes críticos de América Latina, desde Bello hasta Borges, pasando por Rod6 y por Reyes, hayan sido no s6́lo críticos sino promotores de cultura, hayan estado asociados a editoriales, hayan publicado revistas. No sólo han creado su obra de críticos, poetas o narradores. Los cuatro han debido fundar una literatura $(M N 20,57)$.

Los instrumentos más útiles para esta tarea son, sin lugar a dudas, las revistas literarias, y Mundo Nuevo subraya hasta qué punto las publicaciones periódicas han sido importantes en la historia cultural del continente. Así, para comprender la visión plástica de Dario sobre el art nouveau es indispensable hojear la colección del Mundial; Juan Montalvo es El Cosmopolita; Giusti es, con Bianchi, Nosotros; Alfonso Reyes fue "el infatigable redactor unipersonal de Monterrey"; la generación del " 45 " no tiene consistencia mientras no logra romper con Sur y con el suplemento de La Nación, fracasa con Buenos Aires Literaria y se afirma con personalidad propia gracias a Contorno y a Ciudad; Sarduy define su trayectoria cubana desde Orígenes a Ciclón; Cabrera Infante a través de Lunes de Revolución, etc. Las hay buenas y las hay criticables, pero:

las revistas literarias deben ser, entre otras cosas, contradictorias, cabticas, anárquicas, hasta malas: todo ello es la condición para que cumplan su misión de acertar nuevos caminos $(M N 14,76)$.

La "Revista de revistas" de Mundo Nuevo es, así, particularmente interesante, ya que a través de las críticas y elogios de la actividad ajena 
percibimos la justificación de los lineamientos propios, ${ }^{8}$ y una red de comunicaciones, citas, y nombres que van construyendo ágilmente una enciclopedia, un tejido de discurso, un mundo de referencias.

Porque de eso se trata: de soñar un mundoy de realizarlo escrupulosamente. Paralelamente a las novelas que admira, la revista de Emir Rodriguez Monegal construye una realidad de papel. Con un talento de cronista indiscutible basta remitir a las tres piezas maestras del género que se encuentran en Mundo Nuevo: el "Diario del PEN Club", en $M N 4$; el "Diario de Caracas", en $M N 17$ y el "Diálogo en Puerto Azul" en $M N$ 20-, como en un folletín por entregas nos promete primero la información de un congreso, nos la brinda en un número siguiente con abundancia de detalles y la relaciona luego con las reacciones de los participantes en sus publicaciones. Su placer narrativo es manifiesto, y se transmite en el redondeo de las anécdotas, que se convierten en signos de un juego iniciático, como la historia del anillo de Henry James que le prestó León Edel por unos segundos y que se transformó en un ritual para la delegación latinoamericana $(M N 4)$. Los personajes de las intrigas son retratados eficaz y humorísticamente: son esos escritores que se vuelven familiares al lector gracias a las infaltables descripciones físicas, precisas como los trazos de un caricaturista. No faltan las pinceladas de sus costumbres y de sus manías, que nos divierten: Carlos Fuentes que evita viajar en avión cada vez que puede; Onetti, hurañoy desagradable, verdadero quebradero de cabeza para Rodríguez Monegal que ha prometido presentárselo al admirativo y simpático Robles;

\footnotetext{
${ }^{8}$ Zona Franca, por ejemplo, dirigida en Caracas por Juan Liscano, representa un prototipo muy particular de la revista latinoamericana que se dirige simultáneamente al especialista y al gran público: un artículo sobre ciencia ficcion, "verdadera divulgación de la divulgación" está "al lado de los complejísimos y ultrapolisemánticos 'poemas' (o como se llamen) de Severo Sarduy" ( $M N N^{2} 4$ ). Sus au tores hablan simultáneamente dos lenguajes, y logran realizar lo que parece imposible, ser leídos por diferentes públicos. Imagen, también de Venezuela, dirigida por un colaborador de Mundo Nuevo, Guillermo Sucre, tiene "dos coordenadas, América Latina y el mundo" ( $M N$ N20), lo que la lleva a propulsar la literatura y la cultura del continente, utilizando además "las más modernas técnicas de expresión crítica, tales como la entrevista grabada". De Casa de las Américas se habla con sutilezas: su número 35 sorprende por la calidad de la poesf́a que incluye, que, aunque pertenezca al decepcionante "tipo de poesfa que se incrusta fuertemente en la inmediatez, en lo que suele llamarse la actualidad", se destaca; un poema de Fernández está menos logrado, pero "es quizá más sorprendente aún que se pueda hacer una poesía viable con un tema como ése". Se utilizan materiales de revistas respetables: Ercilla, Marcha, Eco, Diálogos, y Siempre; se traducen documentos interesantes de Preuves y de Encounter; se estimula paternalmente a las nuevas publicaciones como Criterio, de Asunción "que no dice cosas realmente muy originales pero tiene la valentía de decirlas en Paraguay", etc. Pero la denuncia es implacable con aquellas revistas que no cumplen con la ética de la profesión: Punto Final, de Santiago de Chile, que publica una entrevista totalmente falsa a Rodríguez Monegal ( $M N$ 20); Visión, de Buenos Aires, que habla de textos que no ha lefdo, manifestando la ignorancia más crasa.
} 
Vargas Llosa, en su búsqueda de un Chinatown de novela policíaca; y la descripción magistral y llena de humor de un Guimarães Rosa digno e imperturbable con su cajita de picnic, sobre una silla precaria en la cubierta de un barco mientras un mare magnum de periodistas y fotógrafos lo arrasaba todo persiguiendo a Neruda. Estos personajes, como en la nueva novela, hablan directamente, en entrevistas grabadas: y aunque el narrador extradiegético parezca desaparecer, no abandona ni por un momento sufonction de régie: selecciona las cintas con un sabio trabajo de montaje, orienta la discusión y, cuando es necesario, toma la palabra como un personaje más, a la manera del narrador de Cambio de piel.

Los acontecimientos que constituyen el eje de la información en cada número son episodios en una trama que podría llevar como título "La lucha por la independencia del intelectual": el escándalo de Los hijos de Sánchez y la destitución de Orfila Reynal como director del Fondo de Cultura Económica; el Congreso del PEN Club en Nueva York; el Congreso de la generación del 60 y la literatura peruana, en Lima; el Congreso Latinoamericano de escritores en México; el Congreso de Caracas y el premio Rómulo Gallegos; el año Rubén Darío; las denuncias sobre la financiación de Mundo Nuevo ; Vietnam; el Plan Camelot; la defensa del erotismo; la reunión de Puerto Azul. Una rúbrica muy lograda que se llama "Sextante"; proporciona la vida misma de premios, congresos, traducciones, casas de edición, polémicas, censura, etc; mundillo imprescindible de información que, a veces, cobra relieve individual en los números siguientes de la revista.

Respeto por los que piensan de manera diferente: Rodríguez Monegal no es peronista, pero en Mundo Nuevo hay un artículo de Rudni sobre Marechal, quien también es entrevistado por Fernández Moreno; detesta el realismo socialista, pero valora la poesía comprometida de Casa de las Américas; es internacionalista, peroestudia en profundidad la obra de David Viñas, integrante de la generación que él llamó "de los parricidas". Rigor: proporcionando la información más completa en torno a las declaraciones de la C.I.A. sobre la financiación del Congreso por la Libertad de la Cultura, que parecian implicar a Mundo Nuevo; indicando casi maniáticamente sus fuentes; estructurando las rúbricas y controlando las informaciones a través de la publicación de las diferentes versiones del mismo acontecimiento. ${ }^{9}$ Pasión: siguiendo la pista secreta de un autor desde la primera lectura de una novela que le fascina: (Grande Sertão: Veredas) hasta un artículo crítico y biográfico lleno de afecto en el momento de la muerte de Guimarães Rosa; dedicando tantos párrafos a narrar la Mesa Redonda de los Escritores Latinoamericanos en el PEN como al detalle del gorrioncito en el motor que retardó el viaje desde París (MN 4); en la

- La única ligereza que podría reprochársele es la de no proporcionar los nombres de los traductores; pero hay que tener en cuenta que no era costumbre hacerlo en las publicaciones perídicas de los años sesenta. 
emoción discreta con la que humaniza un gesto o un momento importante, y en la síntesis que interpreta, siempre, comprometiéndose en primera persona. Cumpliendo con sus propias exigencias, Rodríguez Monegal creó "su" Mundo Nuevo: y en gran medida, el nuestro, el que utilizamos ahora. Analizar si fue totalmente suyo o si integraba líneas discursivas de laépoca o de las instituciones que lo financiaron; si fue siempre coherente o contradictorio; si logró imponerlo totalmente dentro o fuera de su propia revista,osi diferentes discursos rivalizaron con sus artículos, es la tarea de otras investigaciones. Su legado a la historia de la literatura marcó definitivamente un periodo, su poder fue inmenso, y su manera de ejercerlo de una eficacia difícilmente contrarrestada, porque impuso sus propios referentes sobre el significado de la apertura, de la actualidad, de la creación de la independencia, del respeto, del rigor y sobre todo, del apasionamiento.

\section{BIBLIOGRAFIA}

Lambert, José, (1980): "Production, tradition et importation: une clef pour la description de la littérature et de littérature en traduction", Canadian Review of Comparative Literature (Spring 7, 1980), 246-252.

Rodríguez Carranza, Luz, 'L'Individu et l'Institution: Le discours critique des revues littéraires des années 1960 en Amérique Latine" en D. Fokkema y R. Bauer (eds.), Proceedings of the XII ICLA Congress (Ludicium Verlag, 1990).

- "La poétique de Borges et un autre roman historique" en Revue Canadienne de Littérature Comparée (XVI,1, 2, 1990).

- “Comparatismo latinoamericano: una perspectiva pragmática” en Lisa Block de Behhar (coord.) Términos de comparación: los estudios literarios entre historias y teorías (Montevideo: Academia Nacional de Letras, 1991).

Swiggers, Pierre, “A New Paradigm for Comparative Literature”, Poetics Today (3: 1, 1982), 181-184.

Vlasselaers, Joris, (1982) "Suggestions pour une historiographie littéraire ouverte: Commentaire”, en Eva Kushner, ed., Renouvellements dans la théorie de l'histoire littéraire, En Actes du Colloque international (McGill University, 1983), 205-210. 
